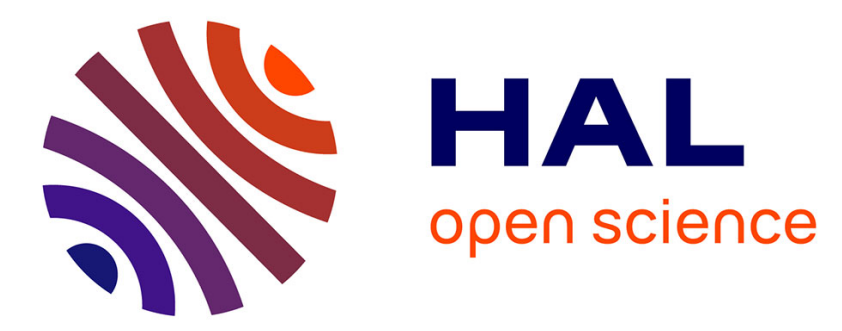

\title{
Applications of Fiber Bragg Grating sensors in the composite industry
}

Pierre Ferdinand, Sylvain Magne, Véronique Dewynter-Marty, Stéphane Rougeault, Laurent Maurin

\section{To cite this version:}

Pierre Ferdinand, Sylvain Magne, Véronique Dewynter-Marty, Stéphane Rougeault, Laurent Maurin. Applications of Fiber Bragg Grating sensors in the composite industry. MRS Bulletin, 2002, 27 (5), pp.400-407. 10.1557/mrs2002.126 . cea-01841910

\section{HAL Id: cea-01841910 https://hal-cea.archives-ouvertes.fr/cea-01841910}

Submitted on 17 Jul 2018

HAL is a multi-disciplinary open access archive for the deposit and dissemination of scientific research documents, whether they are published or not. The documents may come from teaching and research institutions in France or abroad, or from public or private research centers.
L'archive ouverte pluridisciplinaire $\mathbf{H A L}$, est destinée au dépôt et à la diffusion de documents scientifiques de niveau recherche, publiés ou non, émanant des établissements d'enseignement et de recherche français ou étrangers, des laboratoires publics ou privés. 


\section{Applications of Fiber Bragg Grating Sensors in the Composite Industry \\ Pierre Ferdinand, Sylvain Magne, Véronique Dewynter-Marty, Stéphane Rougeault, and Laurent Maurin}

\begin{abstract}
Optical-fiber sensors based on fiber Bragg gratings (FBGs) provide accurate, nonintrusive, and reliable remote measurements of temperature, strain, and pressure, and they are immune to electromagnetic interference. FBGs are extensively used in telecommunications, and their manufacture is now cost-effective. As sensors, FBGs find many industrial applications in composite structures used in the civil engineering, aeronautics, train transportation, space, and naval sectors. Tiny FBG sensors embedded in a composite material can provide in situ information about polymer curing (strain, temperature, refractive index) in an elegant and nonintrusive way. Great improvements in composite manufacturing processes such as resin transfer molding (RTM) and resin film infusion (RFI) have been obtained through the use of these sensors. They can also be used in monitoring the "health" of a composite structure and in impact detection to evaluate, for example, the airworthiness of aircraft. Finally, FBGs may be used in instrumentation as composite extensometers or strain rosettes, primarily in civil engineering applications.
\end{abstract}

Keywords: composite materials, fiber Bragg gratings, laminates, mechanical properties, optical-fiber sensors, optoelectronics, optical properties.

\section{Introduction}

Composite materials have been used for many years in the aerospace industry, owing to their high specific stiffness and strength. They are also used more and more in the transportation industry, and in mechanical engineering and civil engineering for the rehabilitation and reinforcement of structures and cables. Composites display good short-term and long-term (fatigue) mechanical behavior, and good environmental stability (withstanding fire, corrosion, lightning strikes, etc.).

Optical-fiber sensors have been embedded into composite materials for more than 12 years. ${ }^{1}$ For aerospace applications, we may distinguish three main applications for optical-fiber sensors, one related to manufacturing control, a second linked terials, it may be necessary to monitor temperature, pressure, void content, resin front progression, shrinkage, or residual stress, as well as inline cure monitoring (degree of cure). For the last five years, progress has been made in inline manufacturing monitoring by using fiber remote absorption spectrometry ${ }^{3}$ or refractometric methods (Fresnel reflection, slanted fiber Bragg gratings), ${ }^{4,5}$ to such an extent that manufacturers are willing to consider these nondestructive methods in order to shorten the qualification time for new structures, improve the quality of manufacturing, and reduce the number of rejected parts.

Optical-fiber sensors also have been widely investigated for strain monitoring in civil engineering applications (mining, bridges, ${ }^{7-12}$ highways, ${ }^{13}$ and nuclear-power plants ${ }^{14-16}$ ) and for operational monitoring and maintenance of aircraft; ${ }^{17,18}$ once parts are made, the failure modes of the composite structures (e.g., delamination) cannot be predicted analytically and are not well understood. Application of a new composite material is slowed down by high manufacturing costs and risk arising from the inability to predict damage and understand the material's mechanisms, especially in the case of heavily loaded structures. It is also inherently difficult to incorporate a nonintrusive optical connection to a composite part-a problem that has not yet been industrially solved.

This article will focus on recent applications of optical-fiber sensors in composite materials. The industrial aspects are summarized in Table I.

\section{Smart Manufacturing}

In many structures, the key parameter of interest is strain. A fiber Bragg grating (FBG) is formed by exposing the core of a Ge-doped fiber to alternating regions of intense short-wavelength laser light (around $244 \mathrm{~nm}$ ). This is typically done with a high-power UV laser and an interferometer or a phase mask forming an interference pattern imaged on the fiber core. Due to constructive internal interference, an FBG acts as a sharp reflecting filter for a characteristic wavelength (the Bragg wavelength). When subjected to strain, pressure, or a temperature change, the Bragg wavelength of such a filter is shifted proportionally. Accurate measurements of these shifts can be used to extract the strain information, free of temperature influence, if a differential approach is used (e.g., one FBG sensing strain and temperature, and a second FBG only sensing temperature). Moreover, in telecommunication systems, for example, spectral demultiplexing allows the measurement of several Bragg wavelengths reflected by a set of gratings 
Table I: Overview of the Use of Optical-Fiber Sensors in Monitoring Composite Structures.

\begin{tabular}{|c|c|c|c|c|}
\hline & Industry & Applications & Parameters & Specific Problems \\
\hline $\begin{array}{l}\text { Composite } \\
\text { materials: } \\
\text { carbon, } \\
\text { glass-epoxy, } \\
\text { glass-polyester }\end{array}$ & $\begin{array}{l}\text { Aeronautics } \\
\text { Space } \\
\text { Defense } \\
\text { Nuclear power } \\
\text { Transportation (trains, } \\
\text { automobiles, ships) } \\
\text { Civil engineering (e.g., } \\
\text { rehabilitation of } \\
\text { structures) }\end{array}$ & $\begin{array}{l}\text { Smart processing } \\
\text { Quality control } \\
\text { "Health" monitoring } \\
\text { Off-line and on-line } \\
\text { control of } \\
\text { reinforcement in } \\
\text { old structures }\end{array}$ & $\begin{array}{l}\text { Strain/stress } \\
\text { Temperature } \\
\text { Pressure } \\
\text { Degree of cure } \\
\text { Delamination } \\
\text { Internal defects } \\
\text { Impact detection and } \\
\text { damage assessment }\end{array}$ & $\begin{array}{l}\text { Obtaining optical information from structures } \\
\text { in industrial use } \\
\text { Monitoring large structures } \\
\text { Repairing sensors in case of failure or break in } \\
\text { optical fibers } \\
\text { High manufacturing cost of composite } \\
\text { materials } \\
\text { Long-term behavior in harsh environments } \\
\text { (extreme cold, moisture, humidity) }\end{array}$ \\
\hline
\end{tabular}

photo-written on the same fiber (i.e., to form a distributed measurement system).

Today, one of the most important applications for FBG sensing technology is in smart manufacturing - in particular, the control and monitoring of the cure of a composite material. Optical fibers are small enough to be nonintrusive and passive when embedded in a composite. They allow data to be multiplexed from many sensors along a single fiber, and due to the fact that FBGs are able to provide in situ information in real time, they provide a very stable and reproducible measurement (since they are based on a spectral signature). Optical fibers can be embedded in composite materials during the manufacturing process and then used to remotely to measure temperature, strain, pressure, degree of cure, the presence of resin, and other parameters, depending on the process. Among the well-known methods for forming composite structures are by means of autoclave, filament winding, resin transfer molding (RTM), and resin film infusion (RFI). We will discuss some of these next.

\section{Cure Monitoring in an Autoclave}

As an example of an FBG-based smart manufacturing process, we describe here the real-time recording of strain in a composite material, as well as temperature near the composite plate, inside an autoclave used for polymer curing.

For these experiments, a coupon of a typical three-layer composite structure used in aeronautics was prepared in the following way. First, two square layers $(150 \mathrm{~mm} \times 150 \mathrm{~mm})$ of a glass/epoxy skin $1 \mathrm{~mm}$ thick and a foam core $3 \mathrm{~mm}$ thick were glued together. Next, a polyimidecoated FBG $\left(\lambda_{\mathrm{B}}=1310 \mathrm{~nm}\right)$, used as a strain sensor but sensitive to temperature as well, was placed in a U-shaped groove machined in the upper surface of the foam layer. Finally, the second glass/epoxy skin was placed onto the foam and glued. A second FBG $\left(\lambda_{\mathrm{B}}=1305 \mathrm{~nm}\right)$, isolated from strain and spliced in series, was used as a temperature sensor. This FBG was placed outside of but close to the composite sample within the autoclave. ${ }^{19,20}$ The difference of the spectral shift of these two gratings gives the absolute strain inside the composite. Both Bragg wavelengths are monitored with a homemade scanning Fabry-Pérot-based wavelength-division multiplexing (WDM) system, as described in References 2 and 15.

The full curing cycle takes $12 \mathrm{~h}$, including the controlled cooling steps. During the cycle, continuous measurements of temperature and strain are performed. The temperatures measured by the FBG temperature sensor (Figure 1, solid curve) are compared with those given by the autoclave controller (Figure 1, open circles) used for regulating the cure. At the same time, the strain inside the material is recorded (Figure 2). Any induced strain is due to two contributions, thermal expansion and polymer shrinkage, which both result from the curing process.

An easy interpretation of the FBG measurements allows one to identify and control every step of the process. The whole process can be divided into the following steps (see Figure 2):

1. Cycle is initiated at time $t=5 \mathrm{~min}$ by increasing the hydrostatic pressure up to a few bar. This action induces a wavelength shift of $-20 \mathrm{pm}$ for the embedded FBG strain sensor (i.e., a compressive strain), and +50 pm for the FBG temperature sensor in the autoclave. One criticism of the experimental setup is that the optical fiber linked to the temperature sensor is not absolutely free in the pressure chamber, but is firmly attached near the composite sample, which could modify the pressure effect.

2. Temperature is increased to $T_{1}$. The strain sensor records a positive change (maximum $700 \mu \varepsilon$ ), linked to the thermal expansion of the epoxy resin. A somewhat chaotic behavior is observed, perhaps due to a rapid change in the adhesive conditions between the epoxy and the FBG.

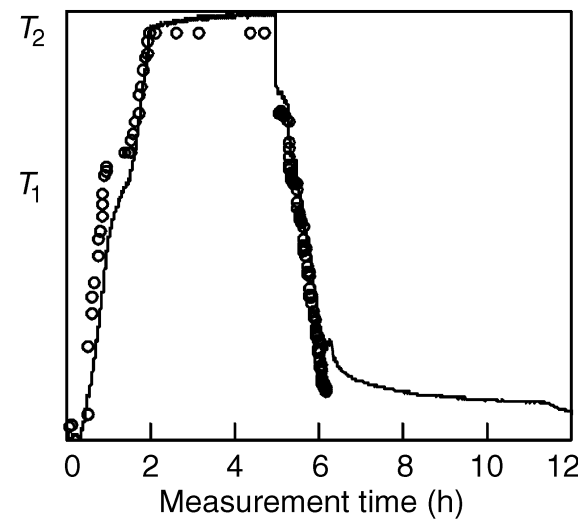

Figure 1. Temperature measurements performed by a fiber Bragg grating (FBG) sensor embedded in a glass/epoxy and foam-core composite during cure in an autoclave (solid curve), compared with the autoclave's controller (open circles). ${ }^{19,20}$

3. Temperature is kept constant at $T_{1}$ for a few tens of minutes. From the curves depicted in Figure 1, the temperature inertia of the autoclave can be estimated by comparing the data given by the temperature sensor and the regulation probe. This inertia could be explained by the fact that the temperature probe in the autoclave is far from the FBG location near the composite plate. On the strain curve, a sudden decrease (Point 3 in Figure 2), down to $-400 \mu \varepsilon$, can be observed. The epoxy polymerization begins and, simultaneously, shrinkage occurs.

4. Temperature is increased from $T_{1}$ to $T_{2}$. The strain sensor shows successive tractions and compressions of about $100 \mu \varepsilon$ in amplitude centered around $-400 \mu \varepsilon$. At this stage in the cure, two phenomena are competing: the material's thermal expansion, due to the temperature increase inducing a positive strain; and the resin shrinkage linked to the ongoing polymerization.

5 . Temperature is kept stable at $T_{2}$ for $3 \mathrm{~h}$. The strain remains constant in the composite. 


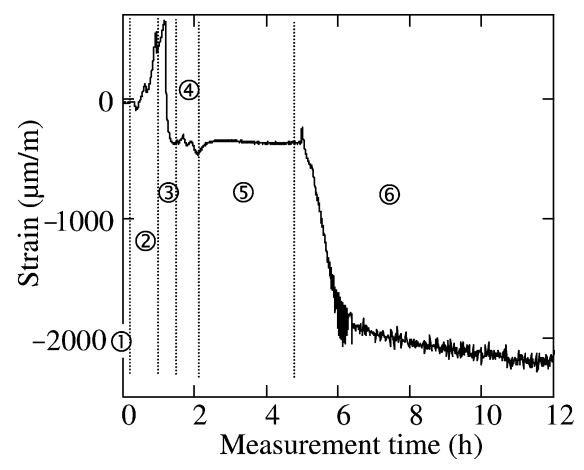

Figure 2. Internal-strain measurements performed by an FBG sensor embedded in a glass/epoxy and foam-core composite during cure in an autoclave, after themal compensation by FBG temperature measurement. ${ }^{19,20}$ (1) Cycle is initiated at time $\mathrm{t}=5 \mathrm{~min}$ by increasing the hydrostatic pressure up to a few bar. (2) Temperature is increased to $T_{1}$. The strain sensor records a positive change (maximum $700 \mu \varepsilon$ ), linked to the thermal expansion of the epoxy resin. A somewhat chaotic behavior is observed, perhaps due to a rapid change in the adhesive conditions between the epoxy and the FBG. (3) Temperature is kept constant at $\mathrm{T}_{1}$ for a few tens of minutes. From the curves depicted in Figure 1, the temperature inertia of the autoclave can be estimated by comparing the data given by the temperature sensor and the regulation probe. This inertia could be explained by the fact that the temperature probe in the autoclave is far from the FBG location near the composite plate. On the strain curve, a sudden decrease down to $-400 \mu \varepsilon$ can be observed. The epoxy polymerization begins and, simultaneously, shrinkage occurs. (4) Temperature is increased from $\mathrm{T}_{1}$ to $\mathrm{T}_{2}$. The strain sensor shows successive tractions and compressions of about $100 \mu \varepsilon$ in amplitude centered around $-400 \mu \varepsilon$. (5) Temperature is kept stable at $\mathrm{T}_{2}$ for $3 \mathrm{~h}$. The strain remains constant in the composite. (6) Temperature is decreased step-by-step. As the temperature decreases, the embedded FBG detects an increasing negative strain from $-400 \mu \varepsilon$ to $-2200 \mu \varepsilon$, due to the resin's thermal compression. This residual compression, which is relatively small, suggests that the properties of the FBG are probably not affected by the embedment in the composite material and that the FBG sensor can be used for other kinds of measurements. See text for additional details.

6. Temperature is decreased step-by-step. As the temperature decreases, the embedded FBG detects an increasing negative strain from $-400 \mu \varepsilon$ to $-2200 \mu \varepsilon$, due to the resin's thermal compression. This residual compression, which is relatively small, suggests that the properties of the FBG are probably not affected by the embedment in the composite material and that the FBG sensor can be used for other kinds of measurements (see the section on "Impact Detection").

Similar results, showing a compression of about $-2400 \mu \varepsilon$, have been previously reported by Dunphy et $\mathrm{al}^{21}$ In the last step, a dramatic decrease in the signal-tonoise ratio occurring at the end of the experiment can be observed. This is due to an optical power decrease, induced by significant stresses (sharp bends, microbends) along the optical fiber supporting the FBGs, that not only considerably reduces the signal-to-noise ratio but also the spectral Bragg peak resolution at the same time. This detrimental effect may occur in textile composites showing periodic microbends. It may be avoided by applying a thicker polymer coating to the fiber.

\section{Smart Resin Transfer Molding Control Process}

In recent years, research laboratories and now the manufacturers of composite structures have perceived the advantages offered by optical-fiber sensors in enhancing the quality of their processes and reducing costs associated with these phases of development. This aspect is particularly acute with regard to the resin transfer molding (RTM) process. RTM is a lowpressure molding process that involves packing layers of dry reinforcement fibers or a preform into a tight mold into which a mixed resin catalyst is injected, followed by thermal polymerization. After curing, the mold can be opened and the composite part removed.

The RTM process allows industrial production of parts to their final dimensions, but the long adjustment phase required to achieve the optimal physical parameters is a drawback to its use. It is rather difficult to guarantee injection of the resin into every part of the mold without leaving dry zones that then become points of structural weakness; furthermore, the high reinforcement-fiber volume implies a very dense composite preform, which makes accurate resin-flow modeling difficult. Moreover, as injection followed by polymerization is done within a closed metallic mold, the possibilities for in situ control are limited. So, the process adjustment requires many prototypes, since only "postmortem" analysis (slicing followed by a microscopic analysis) can provide information feedback on suitable parameters. Such an "open loop" approach is very expensive and time-consuming. Therefore, manufacturers are actively looking for a technique that can provide in situ measurements of the process as the composite is formed. Optical-fiber sensors and FBGs are able to help in this area, as they are small enough to be nonintrusive, they provide very accurate measurements, they are electromagnetically inert, and they allow multiplexing of many sensing points. With these advantages, they look like a decided asset for this type of problem.22

To illustrate this, we next describe a project that uses optical-fiber sensors to supervise the manufacturing airplane propeller blades of the type shown in Figures 3 and 4 . The objective of this project, led by French aeronautics equipment manufacturer Ratier-Figeac in collaboration with the CEA-LIST (the Atomic Energy Commission, Laboratory for Systems and Technology Integration), was to use an advanced measurement system, based on embedded FBG sensor technology, to obtain insights into the process sequence, map resin flow by detecting air-to-resin transitions during the injection, check for dry zones or voids in the structure, and consequently improve the quality of manufacturing and reduce development costs. ${ }^{23}$

In this experiment, 38 FBG sensors were installed in an RTM propeller-blade mold (36 strain sensors and 2 temperature sensors), divided into 4 lines on the face of each blade (Figure 5). The FBG temperature sensors, located at either end of an optical fiber, are based on a CEA proprietary design and make use of an FBG transducer placed inside a microcapillary (20 $\mathrm{mm}$ in length with a 350- $\mu \mathrm{m}$ external diameter) externally coated with polyimide (Figure 6). The optical fiber is maintained at the input of the capillary with a special high-temperature $\left(350^{\circ} \mathrm{C}\right)$ sealing cement. At the other closed end, the fiber is free to move inside the capillary. In this way, the FBG temperature sensor is isolated from mechanical stress induced by the composite structure, enabling differential strain measurements free from the influence of temperature.

At the beginning of the injection process, the temperature difference between the resin and the mold is small (a few degrees Celsius). Consequently, it is not practical to use only thermally induced effects to map resin flow. The useful measurement parameter is the Bragg wavelength shift that happens when the resin flow reaches a sensor location. This effect, however, occurring inside the tightly packed preform in the mold, is small, in either compression or tension. Experimental sensor response ranges between $20 \mu \varepsilon$ and $400 \mu \varepsilon$. These small values make realtime data interpretation difficult, particu- 


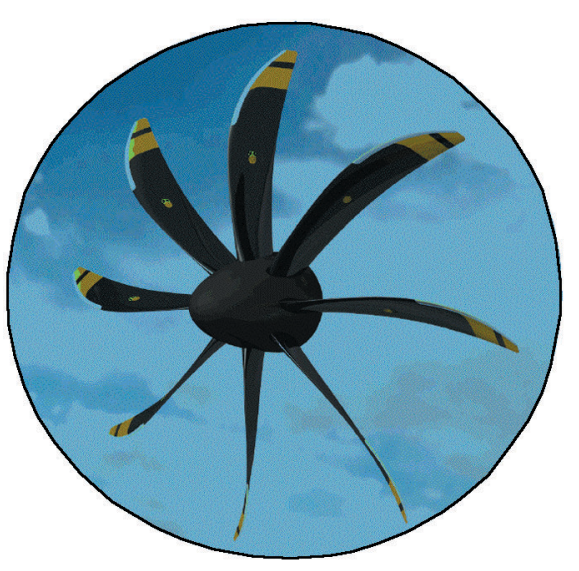

Figure 3. Airplane propeller blade with embedded FBG sensors. Courtesy of Ratier-Figeac, France.

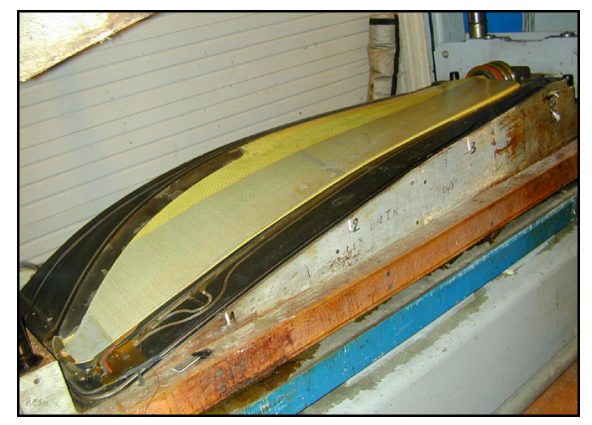

Figure 4. Propeller blade mold, with FBG sensors installed, after curing. Courtesy of Ratier-Figeac, France.

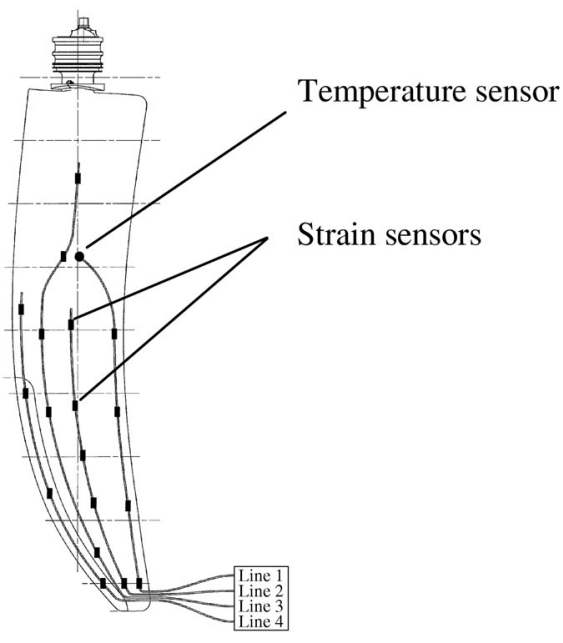

Figure 5. FBG instrumentation on one face of a propeller blade. ${ }^{23}$ larly defining the strain threshold in order to identify the interaction of the resin flow with the sensors. This is the reason why careful postprocessing of the measurements is needed in order to extract valuable results regarding resin-flow behavior.

With this restriction in mind, resin-flow analysis is possible using internal constraint modifications experienced by the optical FBG sensor network, leading to a smart approach in RTM manufacturing. Figure 7 shows the progression of the resin flow in the mold, based on an interpretation of the sensor response.

As a variation of RTM, the resin film infusion (RFI) process is now being used by some manufacturers as an alternative to the usual pre-impregnation processes because it yields improvements in quality and promises a significant cost reduction. In RFI, a dry layer of reinforcement is used along with a cast layer of catalyzed resin. Under pressure and heating, the resin envelops the reinforcement fibers, and thus the part is made. The great benefit of the RFI process is to reduce the void content of the laminate because the dry reinforcement fibers allow air transport out of the stack during polymerization. ${ }^{24}$ It is advantageous for large structures and for the use of high-viscosity resins (which are dif-

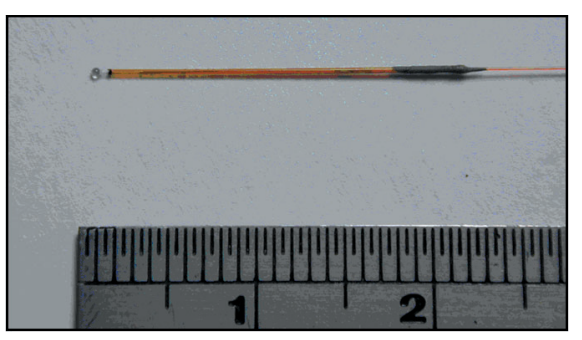

Figure 6. FBG temperature sensor for in situ measurements in a composite propeller blade. Courtesy of CEA/Marty. ficult to work with in traditional RTM). With this new process, optical-fiber sensors and FBGs should be useful in controlling physical parameters such as degree of cure, cure rate, and temperature.

\section{Impact Detection}

For manufacturers and end users of composite structures, a second motivation for using optical-fiber sensors, after manufacturing and testing, is "health" monitoring, that is, evaluating the lifetime of a component or a whole structure. This is essential in applications in which safety is a concern. An example is the radome (nose) of an airplane, which is typically made of a thick, sandwich-type composite structure that is transparent to electromagnetic waves. Optical-fiber sensors and, more specifically, FBG sensors, are potential candidates for nondestructive instrumentation to measure stress and damage in such a structure.

One specific topic concerns the evaluation of permanent damage induced by low-energy impacts (less than 30 J, i.e., too small to cause visible defects on the surface) as well as delamination due to fatigue. ${ }^{19,20}$

The FBG, which is a quasi-distributed sensor localized along the fiber, exhibits a spectral shift proportional to the local permanent strain added to the influence of temperature. The idea is to detect permanent damage characterized by a permanent strain in its surroundings.

To demonstrate the potential of FBGbased instrumentation in the assessment of material integrity following impacts, several composite samples were manufactured with embedded FBGs. One of them includes three embedded FBGs placed $10 \mathrm{~mm}, 30 \mathrm{~mm}$, and $50 \mathrm{~mm}$, respectively, away from the point of impact located in the center of the sample, as described in Figure 8 .
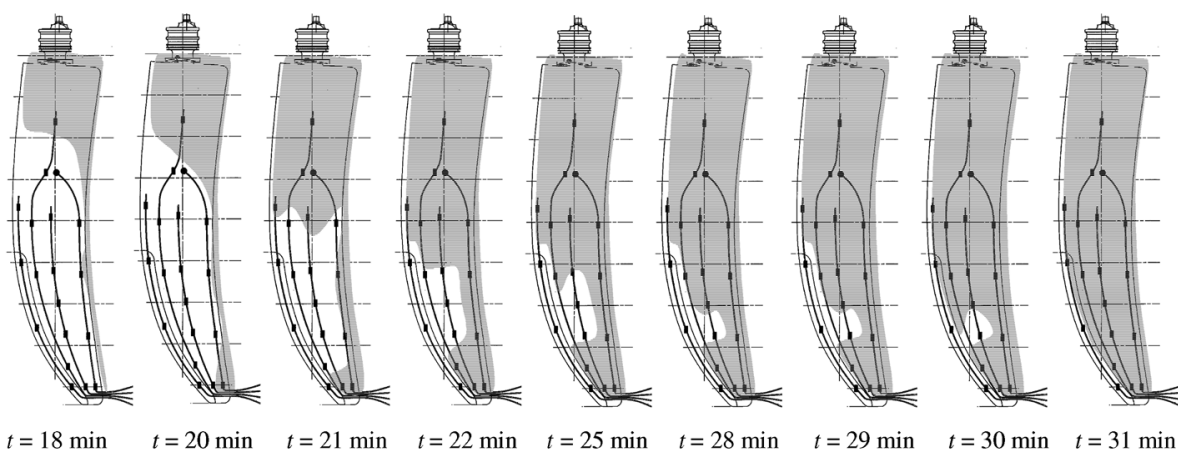

Figure 7. Progression of the resin flow in a propeller blade mold, as inferred from the FBG data. $^{23}$ 
The plate was submitted to nine successive impacts with energies ranging from $2 \mathrm{~J}$ to $20 \mathrm{~J}$. The impact-energy threshold for the three successive FBGs were, respectively, $8 \mathrm{~J}, 10 \mathrm{~J}$, and $12 \mathrm{~J}$ (Figure 9). It is interesting to note the strain saturation for the FBGs, about $-500 \mu \varepsilon$, after the impact of $18 \mathrm{~J}$ in such a sandwich structure.

The method we have developed to record a given permanent defect (invisible on the surface) in sandwich composite material arising from an impact is the first step toward a mapping method able to de-

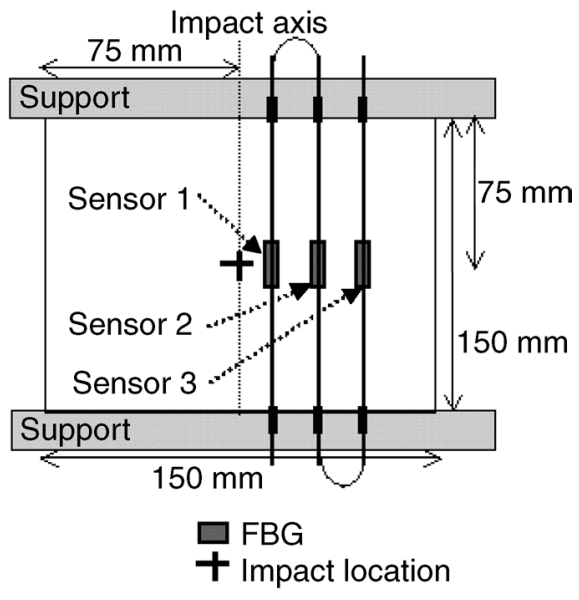

Figure 8. Schematic illustration of a composite plate embedded with three FBG sensors placed $10 \mathrm{~mm}, 30 \mathrm{~mm}$, and $50 \mathrm{~mm}$, respectively, away from a point of impact located in the center of the sample. This setup is used to demonstrate the potential of

FBG-based instrumentation in the assessment of material integrity following impacts. ${ }^{19,20}$ termine and localize all of the defects present in the whole structure. Because the method for measuring impacts is to detect the strains induced by them (primarily internal delamination or foam crushing), the embedded FBG sensing grid needs to be dense enough (typically $10 \mathrm{~cm} \times 10 \mathrm{~cm}$ ) to sense any zone of the structure. The next step in this global damage-detection study is to model the sensor response in order to localize and quantify a given defect by triangulation.

\section{Smart Bogies for Fast Trains}

Mobility is an important factor for economic growth. Enhancing train transportation will become a key issue in future years, as competing means of transportation such as road and air will gradually become saturated in capacity. In a recent study, the German government predicted a saturated situation for these systems within the next 10 years if today's rate of development continues. One consequence may be a load shift of transportation to rail. The European Union is promoting this by developing initiatives and enhancing the competitiveness of the rail grid by means of deregulation and interoperability. This process has been nearly completed in Great Britain, with some consequences. Additionally, the European Union is supporting this process with a planned upgrade to the existing rail network, the Trans-European Net. This will require the upgrade of $40,000 \mathrm{~km}$ of existing rail tracks for use at speeds of up to $200 \mathrm{~km} / \mathrm{h}$ instead of the $160 \mathrm{~km} / \mathrm{h}$ typical today, and the development of $20,000 \mathrm{~km}$ of new rail tracks for use at speeds of greater than $230 \mathrm{~km} / \mathrm{h}$.

Within this framework, some companies in Europe are working to develop new functionalities for trains. In France, Alstom Transport SA, the train division of the Alstom Co., has been working for several months on a new project involving composite materials for a new railcar bogie (Figure 10). Bogies are the swiveling undercarriages at either end of a railroad car on which the wheels are fixed and which serve to damp vibrations transmitted to the car. As we have already discussed, composite materials present many advantages, including lower density and a higher strengthto-weight ratio than metals. However, their use in this area of the transportation industry is new; previously, bogies were made from metallic materials. Consequently, one important part of this development is validating the mechanical behavior of the bogies. A mechanical simulation was led by DDL Consultants (a small company specializing in modeling) with Samcef software; the monitoring technology that achieved the experimental validation was implemented by the Optical Measurements Laboratory of the CEA-LIST, by the use of several optical FBGs during static and dynamic trials.

Several parts of composite bogies were instrumented with in situ FBG sensors. An optical line is composed of several strain FBG sensors for static and dynamic tests, while an extra FBG is devoted to temperature compensation. Accelerated aging tests were carried out by Alstom and the CEA in a climatic chamber to simulate in-use environmental conditions (e.g., cycles of stress, intense cold, heat, moisture, and strong lighting). For these accelerated life tests, an optical line containing three FBG strain sensors and one extra FBG for temperature compensation was embedded during manufacturing of the structural element.

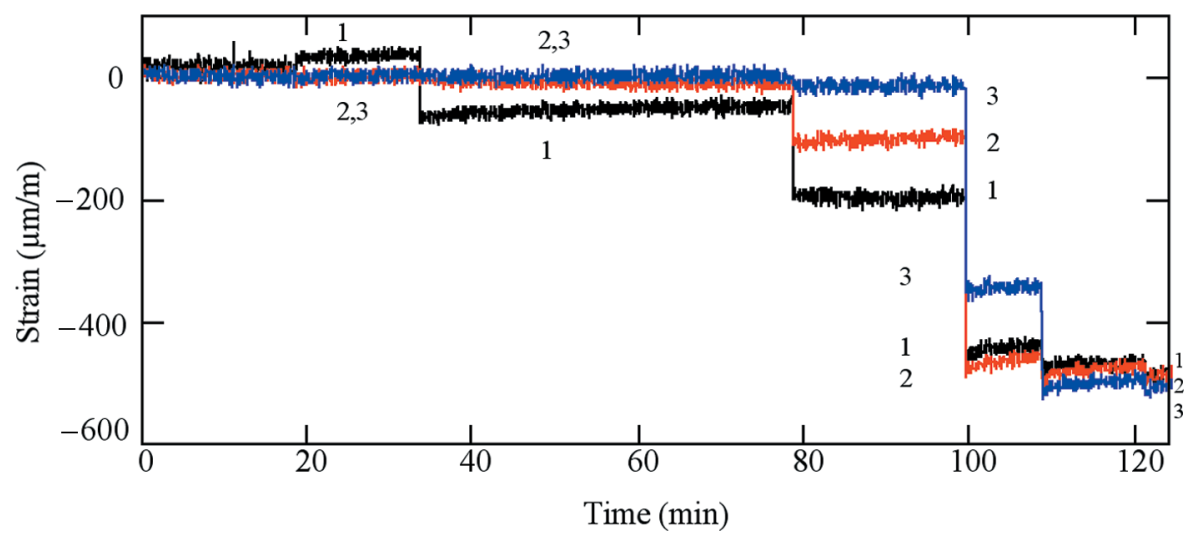

Figure 9. Real-time detection of impacts with energies ranging from $2 \mathrm{~J}$ to $20 \mathrm{~J}$ by means of three FBG sensors (labeled 1, 2, and 3) embedded in a composite material. Each step corresponds to an impact of increasing energy. ${ }^{19,20}$

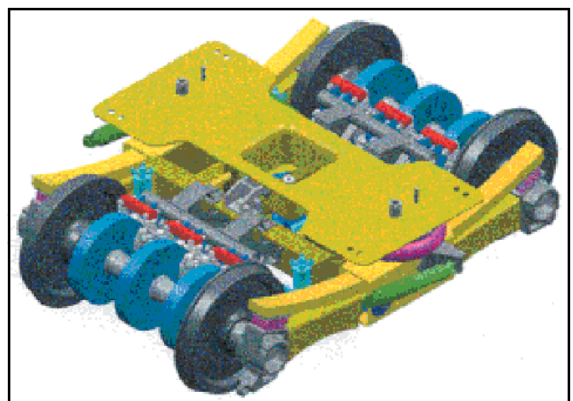

Figure 10. Design of a new composite bogie for fast trains. Bogies are the swiveling undercarriages at either end of a railroad car on which the wheels are fixed and which serve to damp vibrations transmitted to the car. Courtesy of Alstom, France, from Reference 25. 
The stress levels were induced according to three cycles of dynamic loading added to a static one: $27 \mathrm{kN} \pm(8 \mathrm{kN} @$ $7 \mathrm{~Hz}), 32 \mathrm{kN} \pm(10 \mathrm{kN} @ 7 \mathrm{~Hz})$, and $38 \mathrm{kN} \pm(11 \mathrm{kN} @ 7 \mathrm{~Hz})$. The corresponding strain ranged from about $2500 \mu \varepsilon$ up to $3500 \mu \varepsilon$ in the static mode and from $700 \mu \varepsilon$ to $1000 \mu \varepsilon$ in the dynamic mode. The thermal cycles (as specified in the International Union of Railways standard UIC-515-4) were completed every $16 \mathrm{~h}$. The instrumented elements underwent more than 10 million cycles during three weeks of testing, which represents, to our knowledge, the most severe fatigue tests carried out to date with an FBG-based monitoring system. ${ }^{25}$

The results of these experiments showed a perfect agreement of the measurements with the modeling, which proved that these new bogies retain a constant stiffness with no observable aging or mechanicalbehavior evolution (Figure 11).

\section{FBG-Based Strain Rosette}

In the area of strain measurement using FBG sensors, rosettes can be designed to instrument existing composite structures for which embedded sensors are not possible (Figure 12) ${ }^{26,27}$ Rosettes are made of two or three noncollinear strain gauges mounted on a common substrate at $45^{\circ}$ (to form a rectangular rosette) or at $60^{\circ}$ (to form a "delta" rosette).

Such strain rosettes are used extensively in experimental stress analysis to measure the two principal strains (and stresses) and the orientation of the principal axis whenever it is not known a priori. Besides this classical application, we have also described an innovative way to use this rosette as a uniaxial strain gauge that is rigorously independent of temperature ef- fects as well as its orientation on the structure under test. The uniaxial strain, the angular orientation, and the temperature are accurately recovered from data given by the three gauges.

FBG rosettes are potentially easy to manufacture, as they are amenable to batch processing. They may be assembled by hand or automatically using numerical command machines driving a positioning ultrasonic transducer head, leading to mass production. At least two layout designs may be considered. The first design uses one fiber with three Bragg gratings in series and operates in WDM. A second design uses three Bragg gratings in parallel (one fiber for each grating) and operates with an optical switching unit or a parallel analyzer. The bending radius cannot be too small, for reasons of mechanical reliability (the bending radius in Figure 12 is $10 \mathrm{~mm}$ ). The first layout requires the fibers to cross each other, whereas there are no crossings in the second design. Some delta rosette "patches" containing one fiber have been realized in the laboratory, accurately positioned with the help of a reticle (Figure 13). The sides of the delta rosette are $30 \mathrm{~mm}$ long, but a smaller length can be designed. ${ }^{28}$

After positioning, a polyimide cover is applied to the substrate, sealed with acrylic glue, and cured. This second polyimide sheet may leave the fiber triangle (sensing region) partially uncovered for further direct fiber bonding. For industrial applications, we start from a connected optical cable $(0.9 \mathrm{~mm}$ or $3 \mathrm{~mm}$ in diameter) from which the fiber is stripped off for about $30 \mathrm{~cm}$. Then, the fiber may be hydrogenated, and the Bragg gratings are photowritten. The rosette patch is then assembled following the procedure described, except that the cable is sealed so that the patch can be handled as easily as any normal electrical strain-gauge rosette. The polyimide support of the rosette can then be bonded onto metallic parts, stitched onto textiles like a patch, or embedded into composite materials.

\section{Long-Gauge Glass-Epoxy Extensometers}

Fiber-reinforced plastics may also be used as proof-bodies for extensometers. Unlike extensometers with surfacemounted fibers, the sensing fiber is incorporated into the composite material itself during the pultrusion process. ${ }^{29}$ Pultruded structural composites are lighter and more corrosion-resistant than their metallic equivalents, resulting in easier handling and lower cost. Moreover, they are electrically insulated (immune to electromag-

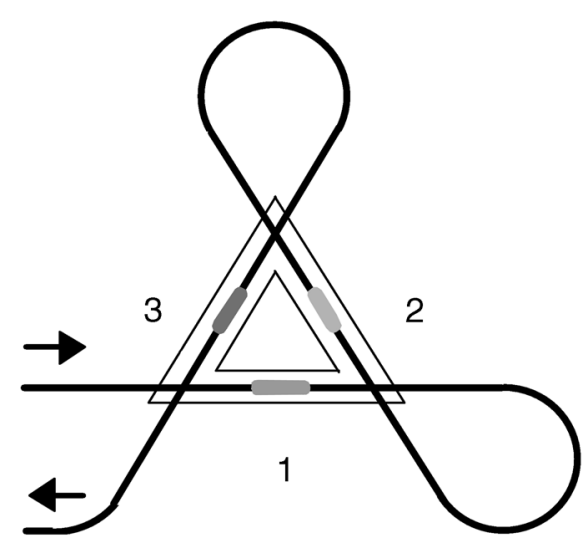

Figure 12. Delta strain rosette with three FBGs. ${ }^{26}$

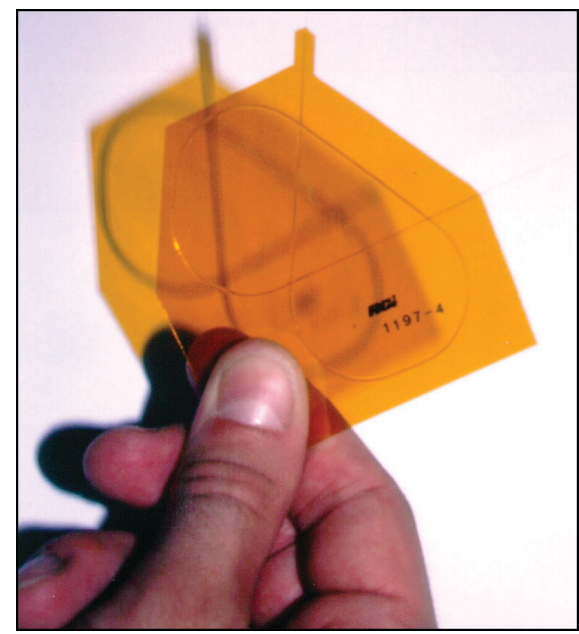

Figure 13. A rosette sensor. Courtesy of CEA/Magne.
Figure 11. Comparison of a numerical simulation with optical FBG measurements. ${ }^{25}$

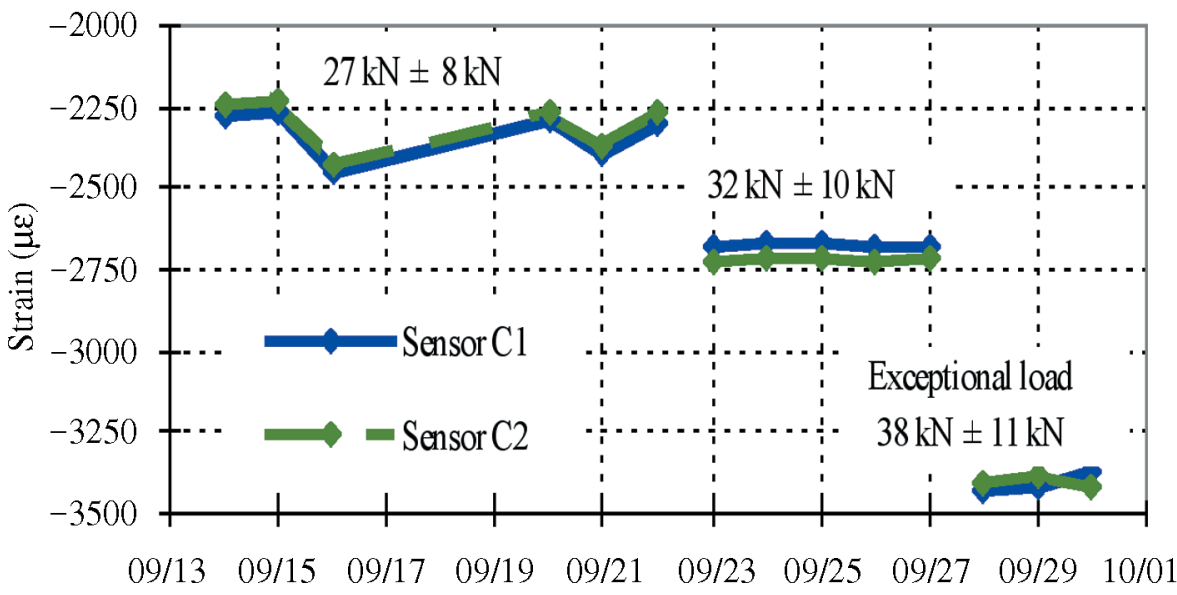


netic interference) and display good mechanical performance (linearity and fatigue). Their mechanical properties depend on the type of reinforcement used (glass, Kevlar), resin type, and profile geometry. The fiber may be located at the center of the composite rod, preserving the fiber from degradation and rendering the measurement free from torsion influence. The fiber runs in and out so that each extensometer may be placed in series along a single cable line and may operate in transmission or in reflection, depending on the network configuration.

In the pultrusion process, parallel glass fibers are bundled and projected through a resin-impregnation furnace and through heating zones. The polymerization is then carefully controlled, as well as the cooling of the composite part. The composite profile may then be cut to the desired length. The composite extensometer has a cylindrical shape, but other profiles may be obtained on demand. Once the composite cylinder is made and cut, threaded sheaths are crimped onto each end. Extensometers are screwed onto fasteners fixed onto concrete or embedded into the concrete while casting (Figure 14).

\section{Conclusions}

Monitoring of composite structures is a 10-year-old activity, still a new technical field in many aspects. Nevertheless, opticalfiber sensors, and particularly fiber Bragg gratings, are being considered more and more often for such purposes, due to their advantages in many industrial composite applications. $^{2}$

In the last decade, a number of national and international research and development programs have addressed the use of optical fibers as temperature, strain, stress, pressure, vibration, and refractive-index sensors, and there are now many prototypes of systems and some products available. The main applications are in aeronautics and transportation as well as in civil engineering sectors. Other applications are found in space (antenna stabilization, shuttle or satellite monitoring, the space station, etc.) and the naval industry. ${ }^{30}$

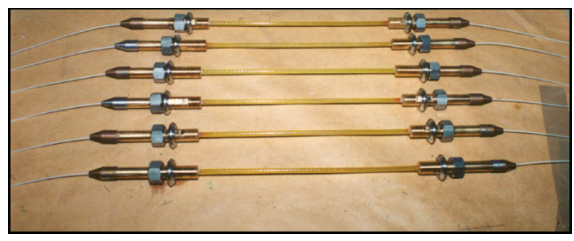

Figure 14. Composite-based FBG extensometers for civil engineering applications. Courtesy of CEA/Magne.
In a few years, a "health diagnosis" of specific or critical parts of any aircraft will be able to be carried out periodically, or on demand according to security requests, thanks to airborne or ground-based FBGbased optical-fiber sensor measurement systems. Such industrial instrumentation will allow one to guarantee the conformity of these parts with respect to their specifications and consequently to certify that an aircraft is or is not able to fulfill its mission. Certainly, the checklist carried out by a pilot before takeoff will integrate new parameters such as structure monitoring.

In this context, research studies are being carried out around the world, relating in particular to enhancing the manufacturing process, ensuring quality control of manufactured elements, and monitoring their health in use (impact detection plus assessment of integrity), as well as achieving cuts in operational and fuel costs.

Indeed, the subject on which the aeronautical sector will focus in the coming years concerns smart (or "intelligent") structures, also called adaptronics. This term relates to all of the means (materials and software) necessary to obtain a better understanding of the real-time parameters involved in any phase of flight, namely, takeoff, cruising, and landing, in order to increase safety, reduce noise, and decrease fuel consumption.

Fiber-optic measurement methods have already shown excellent promise in laboratory tests and in some field trials. Of course, there is a need for scientific research and development to produce some specific sensors, embed fibers routinely, enhance the performance, reliability, and ruggedness of the measurement systems, and reduce their costs. Recent trials have shown that FBG-based optical-fiber sensors offer the possibility of enabling industrial smart-structure technology, as they are able to provide critical information for smart manufacturing, nondestructive evaluation, health monitoring, and damage control. Moreover, they are fully synergistic with the expanding telecommunications market, enabling potential low costs in the mid-term.

\section{References}

1. P. Sansonetti, P. Ferdinand, D.H. Bowen, M. Crowther, B. Culshaw, M. Martinelli, B. Fornari et al., in Proc. SPIE Conf. on Fiber Optic Smart Structures and Skins II (SPIE-The International Society for Optical Engineering, Bellingham, WA, 1989).

2. P. Ferdinand, S. Magne, V. Dewynter-Marty, C. Martinez, S. Rougeault, and M. Bugaud, "Applications of Bragg Grating Sensors in Europe," 12th Int. Conf. on Optical Fiber Sensors (OFS-12), Williamsburg, VA, October 28-31, 1997, p. 14.
3. P.A. Crosby and G.P. Fernando, in Optical Fiber Sensor Technology, Vol. 3: Applications and Systems, edited by K.T.V. Grattan and B.T. Meggitt (Kluwer Academic Publishers, New York, 1999).

4. G. Laffont and P. Ferdinand, Electron. Lett. 37 (5) (2001) p. 289

5. G. Laffont and P. Ferdinand, Meas. Sci. Technol. 12 (7) (2001) p. 765.

6. P. Ferdinand, O. Ferragu, J.-L. Lechien, B. Lescop, V. Marty, S. Rougeault, G. Pierre, C. Renouf, B. Jarret, G. Kotrotsios, M.R.H. Voet, and D. Toscano, "Mine Operating Accurate STABILity Control with Optical Fiber Sensing and Bragg Grating Technology: The BriteEURAM STABILOS Project," 10th Int. Conf. on Optical Fiber Sensor (OFS-10), Glasgow, October 11-13, 1994, p.162; J. Lightwave Technol. 13 (7) (1995) p. 1303.

7. F. Ansari, ed., Proc. Int. Workshop on Fiber Optic Sensors for Construction Materials and Bridges (Technomic, Lancaster, PA, 1998).

8. U. Senhauser, R. Brônnimann, P. Mauron, and P.M. Nellen, in Proc. Int. Workshop on Fiber Optic Sensors for Construction Materials and Bridges, edited by F. Ansari (Technomic, Lancaster, PA, 1998) p. 117

9. S.T. Vohra, M.D. Todd, G.A. Johnson, C.C. Chang, and B.A. Danver, "Fiber Bragg Grating Sensor System for Civil Structure Monitoring: Applications and Field Test," 13th Int. Conf. on Optical Fiber Sensor (OFS-13), Kyongju, Korea, April 12-16, 1999, Paper No. Tu2-1, p. 32.

10. J. Seim, E. Udd, W. Schulz, and H.M. Laylor, "Composite Strengthening and Instrumentation of the Horse Tail Bridge with Long Gauge Length Fiber Bragg Grating Strain Sensors," 13th Int. Conf. on Optical Fiber Sensor (OFS13), Kyongju, Korea, April 12-16, 1999, Paper No. P1-3, p. 196.

11. J. Seim, E. Udd, W. Schulz, and H.M. Laylor, in Proc. SPIE, Vol. 3671 (SPIE-The International Society for Optical Engineering, Bellingham, WA, 1999) p. 128.

12. R.M. Measures, T. Alavie, R. Maaskant, S. Huang, and M. LeBlanc, "Bragg Grating Fiber Optic Sensing for Bridges and Other Structures," 2nd European Conf. on Smart Structures and Materials, Glasgow, 1994, p. 162.

13. R.A. Livingstone, in Proc. Int. Workshop on Fiber Optic Sensors for Construction Materials and Bridges, edited by F. Ansari (Technomic, Lancaster, PA, 1998) p. 3.

14. P. Ferdinand, S. Magne, V. Marty, S. Rougeault, P. Bernage, M. Douay, E. Fertein, F. Lahoreau, P. Niay, J.F. Bayon, T. Georges, and M. Monerie, "Optical Fiber Bragg Grating Sensors for Structure Monitoring within the $\mathrm{Nu}-$ clear Power Plants," presented at the Optical Fiber Sensing and Systems in Nuclear Environments Symposium, SCK-CEN, Mol, Belgium, October 17-18, 1994.

15. V. Dewynter-Marty, S. Rougeault, P. Ferdinand, D. Chauvel, E. Toppani, M. Leygonie, B. Jarret, and P. Fenaux, "Concrete Strain Measurements and Crack Detection with Surface and Embedded Bragg Grating Extensometers," 12th Int. Conf. on Optical Fiber Sensor (OFS12), Williamsburg, VA, October 28-31, 1997, p. 600 .

16. P. Ferdinand, S. Magne, V. Dewynter-Marty, L. Pichon, S. Rougeault, and M. Bugaud, "Opti- 
cal Fiber Sensors Provide New Means for Measurement and Monitoring within the Nuclear Industry," presented at the Int. Nuclear Congress ENC-98, Nice, France, October 25-28, 1998.

17. A. Ball, The Newsletter of the Monitor Consortium (1) (Autumn/Winter 1996) and (2) (Autumn/Winter 1997).

18. A. Ball, in Proc. 4th ESSM and 2nd MIMR Conf., edited by G.B. Tomlinson and W.A. Bullough (Institute of Physics Publishing, Bristol, 1998) p. 435

19. E. Bocherens, S. Bourasseau, V. DewynterMarty, S. Py, M. Dupont, P. Ferdinand, and H. Berenger, in Proc. 4th ESSM and 2nd MIMR Conf., edited by G.B. Tomlinson and W.A. Bullough (Institute of Physics Publishing, Bristol, 1998) p. 381.

20. D. Balageas, S. Bourasseau, M. Dupont, E Bocherens, V. Dewynter-Marty, and P. Ferdinand, J. Intell. Mater. Sys. Struct. 11 (2000) (Part 6) p. 426.

21. J.R. Dunphy, G. Meltz, F.P. Lamm, and W.W. Morey, in Proc. SPIE, Vol. 1370 (SPIEThe International Society for Optical Engineer- ing, Bellingham, WA, 1990) p. 116.

22. V. Dewynter-Marty, S. Rougeault, P. Ferdinand, M. Bugaud, P. Brion, G. Marc, and P. Plouvier, "4 technologies de CFO pour le suivi de fabrication de matériaux composites," presented at the 19th Journées Nationales d'Optique Guidée (JNOG 1999), December 6-8, 1999, Limoges, France (in French).

23. V. Dewynter-Marty, S. Rougeault, P. Ferdinand, M. Bugaud, P. Brion, G. Marc, and P. Plouvier, "Contrôle de la fabrication de pièces en matériaux composites réalisées par procédé RTM à l'aide de capteurs à réseaux de Bragg," presented at the 20th Journées Nationales d'Optique Guidée (JNOG 2000), November 20-22, 2000, Toulouse, France (in French).

24. D. Ness, in Proc. 22nd Int. SAMPE Europe Conf. Soc. for the Advancement of Materials and Process Engineering (La Défense, Paris, 2001) p. 89.

25. L. Maurin, J. Boussoir, S. Rougeault, M. Bugaud, P. Ferdinand, A. Landrot, T. Chauvin, and Y.-H. Grunevald, "Instrumentation de Bogie composite par capteurs à fibers optiques à réseaux de Bragg," presented at the 20th
Journées Nationales d'Optique Guidée (JNOG 2000), November 20-22, 2000, Toulouse, France (in French).

26. S. Magne, S. Rougeault, M. Vilela, and P. Ferdinand, Appl. Opt. 36 (36) (1997) p. 9437. 27. S. Magne, S. Rougeault, M. Vilela, and P. Ferdinand, "Rosettes à réseaux de Bragg et applications," presented at the Journées Nationales d'Optique Guidée (JNOG 1996), October 28-30, 1996, Nice, France (in French). 28. P. Ferdinand, S. Magne, V. Dewynter-Marty, S. Rougeault, and M. Bugaud, "Optical Fiber Bragg Grating Sensors Make Composite Structures Smart," presented at the SAMPE Europe Conf. '99, Paris, April 1999.

29. M. Bugaud, V. Dewynter-Marty, S. Magne, and P. Ferdinand, French Patent No. 2,791,768 (June 10, 2000)

30. K. Pran, G.B. Havgard, R. Palmstrom, G. Wang, G.A. Johnson, B.A. Danver, and S.T. Vohra, "Sea-Test of 27 Channel Fiber Bragg Grating Sensor System on Air Cushion Catamaran," 13th Int. Conf. on Optical Fiber Sensor (OFS-13), Kyongju, Korea, April 12-16, 1999 Paper No. W1-3, p. 145. 